\title{
Tubal Pregnancy with Acute Bleeding Treated by Laparoscopic Surgery: Tips and Case Presentation
}

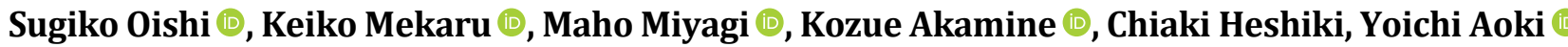 \\ Department of Obstetrics and Gynecology, Graduate School of Medical Science, University of the Ryukyus, Nishihara, Okinawa, \\ Japan \\ Email: h107621@med.u-ryukyu.ac.jp, f041252@eve.u-ryukyu.ac.jp, h097387@med.u-ryukyu.ac.jp, \\ h088421@med.u-ryukyu.ac.jp, yoichi@med.u-ryukyu.ac.jp, chiaki808@gmail.com
}

How to cite this paper: Oishi, S., Mekaru, K., Miyagi, M., Akamine, K., Heshiki, C. and Aoki, Y. (2020) Tubal Pregnancy with Acute Bleeding Treated by Laparoscopic Surgery: Tips and Case Presentation. Open Journal of Obstetrics and Gynecology, 10, 100-107.

https://doi.org/10.4236/ojog.2020.101009

Received: December 6, 2019

Accepted: January 5, 2020

Published: January 8, 2020

Copyright $\odot 2020$ by author(s) and Scientific Research Publishing Inc. This work is licensed under the Creative Commons Attribution International License (CC BY 4.0).

http://creativecommons.org/licenses/by/4.0/

(c) (i) Open Access

\begin{abstract}
Laparoscopic surgery is the standard surgical approach for ectopic pregnancy. However, some surgeons prefer laparotomy for patients with acute bleeding. We evaluated four cases of tubal pregnancy with massive hemoperitoneum $(>800 \mathrm{ml})$ and performed laparoscopic surgery. The patient age ranged from 20 to 37 years, and the gestational age ranged from 5 to 8 weeks. All cases were hemodynamically unstable. Two cases had hemoperitoneum of $>2000$ $\mathrm{mL}$, which was caused by the rupture of the left isthmus tube. In three cases, surgery could be started within approximately $30 \mathrm{~min}$, and in one case, the start time extended owing to difficulty in anesthesia introduction. Moreover, in three cases, the target lesion was reached within $7 \mathrm{~min}$, and the lesion was excised in approximately $20 \mathrm{~min}$ from the start of insufflation, and in one case with a lesion exceeding $7 \mathrm{~cm}$, the time extended. All patients were safely treated via laparoscopic surgery. To initiate surgery without deterioration of the hemodynamic condition, blood transfusion can be started simultaneously with preparation for laparoscopic surgery. Lifting the lesion with a pair of forceps can help immediately stop bleeding, even if it is difficult to secure the visual field owing to massive bleeding. When there is difficulty in anesthesia or a large pregnancy lesion, care should be taken to avoid an increase in the amount of bleeding associated with extension of the perioperative period.
\end{abstract}

\section{Keywords}

Tubal Pregnancy, Acute Bleeding, Laparoscopic Surgery

\section{Introduction}

Ectopic pregnancy is the implantation of an embryo outside the uterine cavity. 
Tubal pregnancy is one of the ectopic pregnancy, which frequency is around $1.3 \%-2.4 \%$ [1] [2]. Treatment strategies involve watchful waiting, surgery, medical treatment such as methotrexate [2]. Surgery is the primary treatment approach for tubal pregnancy with massive hemorrhage. However, deciding between open surgery and laparoscopic surgery remains debatable [3] [4], because of their individual characteristics. These reports indicated that laparoscopic surgery might be difficult owing to unfamiliarity and the learning curves for surgeons, anesthetists, and operation theater nursing staff. In this case report, we present four cases of tubal pregnancy with massive hemoperitoneum that were treated by laparoscopic surgery and provide tips for the treatment of massive hemoperitoneum. All patients had given their consent for the case report to be published.

\section{Case Report}

Patient background is presented in Table 1. The patient age ranged from 20 to 37 years. The gestational age was 5 - 8 weeks from the last menstrual day in cases 1 and 2, and from the ovulation day in case 3. The gestational sac diameter ranged from 20 to $76 \mathrm{~mm}$, and the serum hCG level ranged from 7280 to 15,604 $\mathrm{mIU} / \mathrm{mL}$. In case 2 , serum hCG was not measured because a fetal heartbeat was noted.

Cases 1 and 4 had intra-abdominal hemorrhage of $>2000 \mathrm{~mL}$, and they experienced rupture of the isthmus of the left tube. The shock index (SI) surpassed 1 in all cases, except case 4.

Table 1. Patient characteristics.

\begin{tabular}{|c|c|c|c|c|}
\hline Case & 1 & 2 & 3 & 4 \\
\hline Age (years) & 20 & 37 & 36 & 37 \\
\hline Parity & G0P0 & G3P2 & G2P1 & G1P1 \\
\hline History of operation & - & - & $\begin{array}{l}\text { Laparoscopic } \\
\text { surgery twice }\end{array}$ & $\begin{array}{l}\text { Cesarean } \\
\text { section }\end{array}$ \\
\hline Gestational weeks (weeks) & 5 & 8 & 6 & 8 \\
\hline $\begin{array}{c}\text { Pregnancy site } \\
\text { (all were left tubal pregnancy) }\end{array}$ & Isthmus & Ampullary tube & Ampullary tube & Isthmus \\
\hline Size of the gestational sac $(\mathrm{mm})$ & 30 & 76 & 33 & 20 \\
\hline Fetal heart beat & - & + & - & - \\
\hline Tube rupture & + & - & - & + \\
\hline Serum hCG $(\mathrm{mIU} / \mathrm{mL})$ & 15,604 & $\mathrm{NM}^{*}$ & 6925 & 7280 \\
\hline Blood loss (mL) & 2700 & 1100 & 850 & 2150 \\
\hline Shock index & 1.5 & 1.1 & 1.3 & 0.7 \\
\hline Blood transfusion & + & - & - & + \\
\hline Operation performed & Salpingectomy & Salpingectomy & Salpingectomy & Salpingectomy \\
\hline Length of hospitalization & 12 & 5 & 3 & 4 \\
\hline
\end{tabular}

${ }^{\star}$ Not measured because of fetal heartbeat. 
Tubal pregnancy was confirmed according to serum human chorionic gonadotropin (hCG) levels and ultrasonographic landmarks, including 1) presence of a gestational sac outside of the uterus, 2) an empty uterine cavity, and 3) a clearly visible empty cervical canal.

Laparoscopic surgery was started with necessary preparations or with blood transfusion in parallel. The approach (salpingotomy or salpingectomy) was jointly decided by the surgeon and the patient on consideration of the size of the tubal mass, the desire to have a baby, the history of tubal pregnancy on the ipsilateral side, and the risk of persistent ectopic pregnancy. With regard to the procedure, a laparoscope was inserted into the abdominal cavity from a $10-\mathrm{mm}$ umbilical incision using the open access technique, and three additional trocars were introduced at the lower portion of the abdomen under direct vision. An adequate visual field was established by creating pneumoperitoneum at a pressure of $8 \mathrm{mmHg}$.

However, the massive hemoperitoneum caused difficulty securing the visual field. Bleeding may be immediately stopped by lifting the pregnancy lesion with a pair of forceps (Figure 1(a), Figure 1(b)).

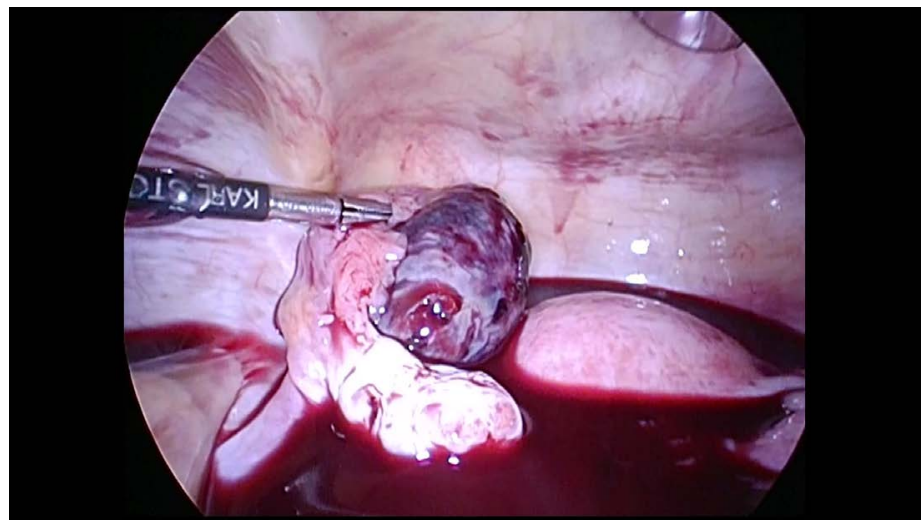

(a)

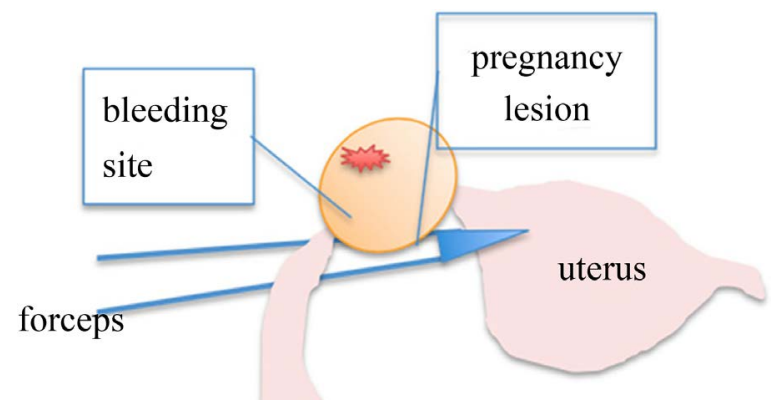

tube

(b)

Figure 1. (a) Approach to confirm a pregnancy lesion. Operative findings of case 1. Isthmus pregnancy of the left tube: scooping before vacuuming the blood; (b) Illustration of (a). 
The surgical approach was decided after consultation with the anesthesiologist and after taking into consideration the patient's characteristics.

According to the system for emergency surgery, laparoscopic surgery is possible $24 \mathrm{~h}$ through the on-call system for obstetricians and anesthesiologists.

Case 1 was a 20 -year-old woman who was 5 weeks pregnancy. She experienced massive hemoperitoneum owing to rupture of the isthmus related to pregnancy. Considering that the dorsal position is difficult to execute owing to abdominal pain, the patient was intubated in the lateral decubitus position. On the other hand, the time spent from entering the operating room to starting surgery by anesthesia introduction was $57 \mathrm{~min}$. The abdominal hemorrhage volume was $2700 \mathrm{~mL}$. The clots were difficult to vacuum, but the lesion was identified by scooping the left tube without vacuuming all clots (Figure 1(a)). Considering a diagnosis of isthmus tube rupture, we performed left salpingectomy. The preoperative SI was 1.5, and we started blood transfusion before the surgery to prevent deterioration of the hemodynamic condition. The patient received 6 units of red blood cells, 10 units of fresh-frozen plasma, 15 units of platelets, and 3000 units of antithrombin III. The patient required 10 days of hospitalization after surgery without any treatment because of pleural effusion and atelectasis owing to rapid blood transfusion.

Case 2 was a 37 -year-old woman who was 8 weeks pregnant. The lesion was left ampullary tube and the maximum size of the gestational sac was $76 \mathrm{~mm}$. This case is the only case that confirmed fetal heart beat. Considering a diagnosis of left ampullary tube pregnancy, we performed left salpingectomy. Blood inside of abdomen was vacuumed to secure the field of view before lifting the fallopian tube, and thus, the operative time increased as $141 \mathrm{~min}$. However, the time from starting surgery to starting insufflation was fast as $4 \mathrm{~min}$. The abdominal hemorrhage volume was $1100 \mathrm{~mL}$.

Case 3 was a 36-year-old woman who was 6 weeks pregnant. She got pregnant after internal uterine insemination at our hospital. We considered a diagnosis of left ampullary tube pregnancy, we performed left salpingectomy. The abdominal hemorrhage volume was $850 \mathrm{~mL}$. Although the preoperative SI was 1.3, blood transfusion was not needed.

Case 4 was a 37-year-old woman who was 8 weeks pregnant. Owing to sudden abdominal pain, she was transported by ambulance to the hospital. Her blood pressure was 79/39 $\mathrm{mmHg}$, which was low. Her pulse rate was 52 beats/min, and the SI was 0.7. Vaginal ultrasonography showed the gestational sac close to the left ovary, and it was not inside the uterus. Intra-abdominal hemorrhage was noted, with an estimated volume of $>1000 \mathrm{~mL}$. The time spent from entering the operating room to starting surgery was $18 \mathrm{~min}$, and the time spent from starting surgery to starting insufflation was $2 \mathrm{~min}$. The left tube was scooped before vacuuming all the blood, and we could reach the lesion. A left isthmus tubal pregnancy was noted, and left salpingectomy was performed. The patient received 4 units of red blood cells, 4 units of fresh-frozen plasma, and 1500 units of antith- 
rombin III. Her vital signs were stable during and after the surgery. All cases were completely treated by laparoscopic surgery. None of these patients had persistent ectopic pregnancy.

The operative time of each case is shown in Table 2. The average time spent from entering the operating room to starting surgery by anesthesia introduction and facility apparatus preparation was $33 \pm 9 \mathrm{~min}$. In case 1 , the anesthesia time was extended owing to difficulty in maintaining the position for abdominal pain. From the start of insufflation, we reached the lesion within $7 \mathrm{~min}$ in cases 1, 3, and 4 . However, in case 2, blood was vacuumed to secure the field of view before lifting the fallopian tube, and thus, the time increased. The tips to shorten the operation time and avoid increasing hemorrhage were leaching and stopping bleeding by grapping the lesion as soon as possible.

\section{Discussion}

Deciding between laparoscopic surgery and open surgery for ectopic pregnancy is controversial because each approach has its own characteristics [3] [4]. Although laparoscopic surgery is less invasive than open surgery, the former might depend on the technique of the surgeon and the status of facilities, including the preparation of the equipment, before bleeding is controlled. Open surgery has been generally preferred in hemorrhagic shock cases [5]. However, technical improvements and interest in minimally invasive treatments have raised the demand for laparoscopic surgery, and it has advanced to adaptive expansion rapidly in recent years [6].

Various reports have compared laparoscopic surgery with laparotomy [7] [8] [9] [10], and these reports have identified many advantages of laparoscopic surgery and its non-inferiority when compared with laparotomy. In particular, smaller bleeding amount; shorter operative time, hospitalization duration, and recovery duration; and lower pain were suggested for laparoscopic surgery when compared with laparotomy (Table 3).

In the present study, the median hospitalization duration of the four laparoscopic surgery cases was 4.5 days (range, 3 - 12 days). In open surgery cases, the hospitalization duration is generally a minimum of 7 days. Hence, the burden on patients is lower with laparoscopic surgery than with open surgery.

Tubal pregnancy is the most common ectopic pregnancy, accounting for over

Table 2. The time from entering the operation room to excision of the ectopic lesion.

\begin{tabular}{ccccc}
\hline Case & 1 & 2 & 3 & 4 \\
\hline Entering the OR to staring surgery (min) & 57 & 37 & 18 & 20 \\
Operative time (min) & 75 & 141 & 88 & 105 \\
Starting surgery to starting insufflation (min) & NA & 4 & NA & 2 \\
Starting insufflation to arriving at the lesion (min) & 5 & 20 & 5 & 7 \\
Starting insufflation to excising the lesion (min) & 24 & 50 & 24 & 20 \\
\hline
\end{tabular}

OR: operating room, NA: not available. 
Table 3. Reports comparing laparoscopic surgery with laparotomy.

\begin{tabular}{|c|c|c|c|c|}
\hline & & $\begin{array}{l}\text { No dominance of } \\
\text { laparoscopy and laparotomy }\end{array}$ & Advantage of laparoscopy & $\begin{array}{l}\text { Disadvantage } \\
\text { of laparoscopy }\end{array}$ \\
\hline Cohen et al. (2013) & $\begin{array}{l}\text { Laparotomy }(\mathrm{n}=48) \text { vs. laparoscopic } \\
\text { surgery }(\mathrm{n}=12) \text { for ectopic pregnancy } \\
\text { with hemoperitoneum }>800 \mathrm{~mL}\end{array}$ & $\begin{array}{l}\text { Preoperative and postoperative } \\
\text { hemoglobin levels, blood } \\
\text { transfusion quantity, } \\
\text { complication frequency, and } \\
\text { hospitalization duration }\end{array}$ & $\begin{array}{l}\text { Amount of bleeding was } \\
\text { lower and operative time } \\
\text { was shorter }\end{array}$ & Not available \\
\hline Beuran et al. (2016) & $\begin{array}{l}\text { Laparotomy }(\mathrm{n}=28) \text { vs. laparoscopic } \\
\text { surgery }(\mathrm{n}=27) \text { for ruptured tubal } \\
\text { pregnancy and ruptured ovarian cyst with } \\
\text { massive hemoperitoneum }>500 \mathrm{~mL}\end{array}$ & $\begin{array}{l}\text { Degree of hemoglobin level } \\
\text { reduction, blood transfusion } \\
\text { quantity, postoperative } \\
\text { complication rate }\end{array}$ & Not available & Not available \\
\hline $\begin{array}{l}\text { Snyman et al. (2017, } \\
\text { randomized trial) }\end{array}$ & $\begin{array}{l}\text { Laparotomy }(\mathrm{n}=69) \text { vs. laparoscopic } \\
\text { surgery }(\mathrm{n}=70) \text { for ectopic pregnancy } \\
\text { involving rupture }\end{array}$ & Frequency of blood transfusion & $\begin{array}{l}\text { Hospitalization duration } \\
\text { and recovery duration were } \\
\text { shorter and pain was lower }\end{array}$ & $\begin{array}{l}\text { Operative time was } \\
\text { longer }(67.3 \mathrm{~min} \text { vs. } \\
30.5 \mathrm{~min}, p<0.0001)\end{array}$ \\
\hline
\end{tabular}

95\% of cases [11]. However, the risk of bleeding varies according to the pregnancy site. Thus, preoperative evaluation and diagnosis are important. Among the four cases in this report, two that had a bleeding volume of $>2000 \mathrm{~mL}$ were diagnosed with isthmus tube pregnancy, which might be associated with increased bleeding when compared with that for ampullary tube pregnancy.

All cases presented SI $>1$ or low blood pressure, and two cases needed blood transfusion. Even the cases that present bleeding volume of $>2000 \mathrm{ml}$ and SI $>1$ may be treated by laparoscopic surgery with appropriate hydration and blood transfusion.

Although the ampullary and fimprial pregnancies are the most common sites of ectopic pregnancy [11], two of four cases were isthmic pregnancies in current report. There is a report that the risk of ruptured ectopic pregnancy was greater for cornual and isthmic pregnancies compared with ampullary-fimbrial pregnancies, but logistic regression analysis identified no significance [12].

Presently, we do not adopt autologous blood transfusion for ectopic pregnancy to prevent amniotic fluid and villus contamination. However, some reports have suggested the feasibility of autologous blood transfusion for ectopic pregnancy [13] [14].

\section{Conclusion}

We encountered four cases of tubal pregnancy with massive intra-abdominal hemorrhage, and they were successfully treated by laparoscopic surgery. To initiate surgery without deterioration of the hemodynamic condition, blood transfusion can be started simultaneously with preparation for laparoscopic surgery. Lifting the pregnancy lesion with a pair of forceps can help immediately to stop bleeding, even if it is difficult to secure the visual field owing to massive bleeding. When there is difficulty in anesthesia or isthmus pregnancy, care should be taken to avoid an increase in the amount of bleeding associated with extension of the perioperative period. 


\section{Conflicts of Interest}

The authors declare no conflicts of interest regarding the publication of this paper.

\section{References}

[1] Saraiya, M., Berg, C.J., Shulman, H., Green, C.A. and Atrash, H.K. (1999) Estimates of the annual Number of Clinically Recognized Pregnancies in the United States, 1981-1991. American Journal of Epidemiology, 149, 1025-1029. https://doi.org/10.1093/oxfordjournals.aje.a009747

[2] Taran, F.A., Kagan, K.O., Hubner, M., Hoopmann, M., Wallwiener, D. and Brucker, S. (2015) The Diagnosis and Treatment of Ectopic Pregnancy. Deutsches Ärzteblatt international, 112, 693-703. https://doi.org/10.3238/arztebl.2015.0693

[3] Lundorff, P., Thorburn, J., Hahlin, M., Källfelt, B. and Lindblom, B. (1991) Laparoscopic Surgery in Ectopic Pregnancy. A Randomized Trial versus Laparotomy. Acta Obstetricia et Gynecologica Scandinavica, 70, 343-348. https://doi.org/10.3109/00016349109007885

[4] Snyman, L.C., Makulana, T. and Makin, J.D. (2017) A Randomized Trial Comparing Laparoscopy with Laparotomy in the Management of Women with Ruptured Ectopic Pregnancy. SAMJ, 107, 258-263. https://doi.org/10.7196/samj.2017.v107i3.11447

[5] Carson, S.A. and Buster, J.E. (1993) Ectopic Pregnancy. New England Journal of Medicine, 329, 1174-1181.

[6] Rizzuto, M.I., Oliver, R. and Odejinmi, F. (2008) Laparoscopic Management of Ectopic Pregnancy in the Presence of a Signify Haemoperitoneum. Archives of Gynecology and Obstetrics, 277, 433-436. https://doi.org/10.1007/s00404-007-0473-7

[7] Gray, D.T., Thorburn, J., Lundorff, P., Strandell, A. and Lindblom, B. (1995) A Cost-Effectiveness Study of a Randomized Trial of Laparoscopy versus Laparotomy for Ectopic Pregnancy. Lancet, 345, 1139-1143. https://doi.org/10.1016/s0140-6736(95)90977-x

[8] Brumsted, J., Kessler, C., Gibson, C., et al. (1988) A Comparison of Laparoscopy and Laparotomy for the Treatment of Etopic Pregnancy. Obstetrics \& Gynecology, 71, 889-892.

[9] Cohen, A., Almog, B., Satel, A., et al. (2013) Laparoscopy versus Laparotomy in the Management of Ectopic Pregnancy with Massive Hemoperitoneum. International Journal of Gynecology and Obstetrics, 123, 139-141. https://doi.org/10.1016/j.ijgo.2013.05.014

[10] Beuran, M., Negoi, I., Hostiuc, S., et al. (2016) Laparoscopic Approach Has Benefits in Gynecological Emergencies-Even for Massive Hemoperitoneum. Chirurgia, $111,48-53$.

[11] Marion, L.L. and Meeks, G.R. (2012) Ectopic Pregnancy: History, Incidence, Epidemiclogy, and Risk Factors. Clinical Obstetrics and Gynecology, 55, 376-386. https://doi.org/10.1097/grf.0b013e3182516d7b

[12] Nadine, J., Hervé, F., Jean, B., Jean-Luc, P., Elisabeth, G. and Joël, C. (1999) Ruptured Tubal Ectopic Pregnancy: Risk Factors and reproductive Outcome. American Journal of Obstetrics \& Gynecology, 180, 938-944.

[13] Takeda, A., Manabe, S., Mitsui, T. and Nakamura, H. (2006) Management of Patients with Ectopic Pregnancy with Massive Hemoperitoneum by Laparoscopic 
Surgery with Intraoperative Autologous Blood Transfusion. Journal of Minimally Invasive Gynecology, 13, 43-48. https://doi.org/10.1016/j.jmig.2005.09.100

[14] Yamada, T., Okamoto, Y., Kasamatsu, H. and Mori, H. (2003) Intraoperative Autologous Blood Transfusion for Hemoperitoneum Resulting from Ectopic Pregnancy or Ovarian Bleeding during Laparoscopic Surgery. JSLS, 7, 97-100. 